\title{
Casi siglo y medio de recepción tradicionista: Universalidad o internacionalidad de Ricardo Palma
}

\author{
Miguel Ángel Vega Cernuda \\ Universidad de Alicante \\ Carsacer@gmail.com \\ Alicante-España
}

\section{Resumen}

Este trabajo examina las categorías de universalidad e internacionalidad de la obra de Ricardo Palma. Se trata de un análisis de la fenomenología de la recepción de las Tradiciones en el que se han aplicado ideas y procedimientos de la emergente Bibliometría de la literatura científica para mostrar el considerable desfase de la presencia de las obras de Palma en las letras hispánicas (editorialismo, crítica, etc.) con respecto a las universales (ediciones en otras lenguas).

Palabras: Tradiciones peruanas, universalidad, internacionalidad, Bibliometría, editorialismo, traducción.

\section{Abstract}

This paper examines the universality and internationality categories of Ricardo Palma's work. It is an analysis of the phenomenon in the reception of the Traditions. Ideas and procedures from the emerging Bibliometrics of scientific literature have been applied to show the considerable gap between the presence of Palma's works in the Hispanic letters (editorialism, criticism, etc.) compared to the universal ones (editions in other languages).

Keywords: Peruvian traditions, universality, internationality, Bibliometrics, editorialism, translation. 
Miguel Ángel Vega Cernuda (España): Profesor Titular (U. Complutense). Catedrático (U. de Alicante, actualmente jubilado. Estudios de Filosofía y Teología (1960-1966). Estudios de Filología Moderna (Licenciado en Filología Moderna. 19691973) en U. Complutense. Becado en Tubinga (DAAD, 197375), Viena (ÖAD, 1980) y Berlín (DAAD, 1985). Doctor en Filología Alemana. Estancias de formación en Nimega, Perugia, Gante, Oxford, Lübeck (DAAD), Arles, Procida, Aarhus. Diversas distinciones internacionales. Profesor visitante de la U. de Münster (200-2012). Director del Instituto Universitario de Traductores Complutense (1987-2003) Autor de un centenar de artículos y una docena de libros. (Temas: literaturas en lengua alemán, historia y teoría de la traducción, literatura misionera). Traductor literario (treinta títulos del alemán, italiano, francés, danés: Casanova, Jacobsen, Goethe, Schnitzler. Haertling, etc.) 


\section{El lector como autor o la internacionalidad de Palma}

A las Tradiciones de Ricardo Palma me gusta acercarme más como lector desprevenido -es decir, por puro placer y al margen de consideraciones intelectuales- que como crítico. Y por supuesto, también como investigador de la historia de la traducción. En esta ocasión comparezco ante ustedes para dar una opinión -discutible pero justificada con datos- acerca de la "universalidad" de nuestro autor, que juzgo muy inferior a su "internacionalidad" y, en todo caso, insuficiente. En efecto, entre ambas categorías, internacionalidad y universalidad, existe en el caso de Ricardo Palma un evidente y considerable desfase o décalage. El contraste entre la presencia de las Tradiciones en el interior de las letras hispánicas -editorialismo, crítica, recepción bibliófila, etc.- y su presencia en las letras universales -a través de la versión a otras lenguas- viene marcada por una innegable desproporción. Por eso, para justificar este juicio referido al estado de la obra de Palma, me van a permitir un breve análisis de la fenomenología de su recepción, en el que aplicaré analógicamente a este escrito de carácter humanístico algunas de las ideas que orientan en la actualidad la emergente Bibliometría de la literatura científica.

Hay otra consideración crítica que me mueve a la hora de cumplir esta tarea, a saber, la de que la obra literaria, toda obra literaria, tiene dos autores: el escritor y los lectores, y, entre estos últimos, de manera especial, el protolector o editor. Es esta una propuesta que recientemente ha reavivado, por ejemplo, una insigne pluma de las letras hispánicas, Javier Cercas, premio Planeta 2019. Por eso, para dar cumplida cuenta del propósito que guía este encuentro, la revisión de las Tradiciones, cuando se me encargó la participación en esta mesa, me pareció oportuno estudiar el grado de autoría que el lector ha tenido en el estado social de la obra ricardopalmista, hacer una detenida cala en los signos de recepción de la obra, realizando una serie de visitas 
-reales unas: a la BNE de Madrid y al IAI de Berlín; virtuales otras: a los catálogos de diversas bibliotecas, la BNP de Lima, la BNA de Buenos Aires, etc.- así como al mejor catálogo bibliográfico mundial, el de Karlsruhe (el KVK) para comprobar y calibrar el estado de la cuestión que tratamos, documentándola sobre datos fiables.

En esas visitas pude comprobar cómo la obra de Palma constituye un capítulo aparte de la historia del libro y cabría decir que las Tradiciones configuran una particular especie de "microcosmos bibliográfico". Con el material bibliográfico tradicionista sería viable crear un archivo específico, quizás en el marco de lo que los italianos llaman "parque literario", institución dedicada a la documentación y propagación de la personalidad y obra de autores italianos ${ }^{1}$. Es esta una percepción que inmediatamente se obtiene al observar la cantidad y cadencia de las ediciones; el número de documentos bibliográficos primarios de las Tradiciones presentes en las bibliotecas y contrastarlos con la presencia de otras obras y autores en las bibliotecas consultadas. A los cien años de la muerte de Ricardo Palma, apenas hay un año en el que no aparezcan en el mercado una o varias ediciones de las Tradiciones.

Con el objeto de visualizar una perspectiva del desarrollo histórico y cualitativo de la recepción social de la obra, hemos reducido esos documentos a una tabla, elemental pero suficiente, que parte del año 1883, año en el que se empieza a editar las Tradiciones como obra completa (Imprenta del Universo Carlos

l El término "parco letterario" designa en italiano un centro de información, documentación y difusión de la obra de un autor y establecido en un entorno temática o biográficamente relacionado. Así, por ejemplo, la isla de Procida, escenario de L'Isola di Arturo, alberga un parque literario dedicado a la obra de Elsa Morante. Lo mismo sucede con Deledda en Nuoro (Cerdeña) o Leopardi en Recanati (Las Marcas). Así hasta una quincena de parques. 
Prince $)^{2}$. Además de repasar la historia de la recepción editorial de la obra, permite la formulación de una serie de afirmaciones caracterizadoras de esa recepción.

1) La primera y más fenoménica percepción es la constatación de la presencia masiva de la obra en el editorialismo hispanohablante: en los cien años que van desde el fallecimiento del autor hasta el presente, los registros de los catálogos de la Biblioteca Nacional de España, la Nacional del Perú, la Nacional de Buenos Aires, el IAI (Ibero-amerikanisches Institut) de Berlín y el KVK (Karlsrher Virtueller Katalog), se pueden identificar casi dos centenares de documentos bibliográficos cuyo contenido son las Tradiciones peruanas, la mayoría de los cuales corresponden a ediciones o reimpresiones parciales que normalmente no superan el centenar de páginas. Todo ello hace del creador del "tradicionismo" un caso, si no único, sí raro de recepción: masiva pero reducida.

2) Un segundo juicio se refiere a la rapidísima internacionalización de la edición tradicionista en el ámbito hispano. Desde que, ya a finales del siglo XIX, cuajara la maniera literaria de Ricardo Palma, su peculiaridad literaria, las Tradiciones traspasaron las fronteras peruanas, siendo sus primeras irrupciones internacionales las ediciones neoyorkina (1883), argentina (1891) y chilena (1903), y la española de Montaner y Simón (1893-94-96), que el propio autor dirigió. Con ello, la obra traspasó el horizonte del "lector implícito" inmediato, de su destinatario, ampliando un arco de "receptores" quizás no previsto. Ya en pleno siglo XX, su recepción internacional experimentó una progresión geométrica. No resultaría atrevido decir

2 Ver "Cronología” en la edición de las Tradiciones de Pedro Díaz (2008). 
que incluso hoy las Tradiciones gozan, si consideramos su extensión, de aquel boom editorial del que en los años 70/80 gozaba la literatura hispanoamericana. Y cabría conjeturar que Palma quizás sea, con el premio nobel peruano Vargas Llosa, el autor más editado, reimpreso y leído de las letras peruanas. E indicio de esa internacionalización es también el hecho de que muchas bibliotecas nacionales de los países no hispanos poseen un número importante de ediciones tradicionistas... en español. Así, por ejemplo,

- en Austria, la Biblioteca Nacional de Viena alberga 4 ejemplares de cuatro ediciones diferentes de las Tradiciones;

- en Alemania, en el Instituto Ibero-americano, se registran 70 ejemplares de 24 diferentes ediciones; en la Staatsbibliothek de Berlin existen 14 registros de diferentes ediciones; la Deutsche National Bibliothek de Leipzig 3 ediciones;

- en Italia, la Biblioteca Nazionale Centrale de Roma guarda 3 títulos tradicionistas... y una versión en italiano;

- en Bélgica, en la Bibliothèque Royale de Bruselas, 4 ejemplares de cuatro ediciones distintas... y una versión en francés;

- en Francia, la Biblioteque National de París, 13 y dos traducciones al francés.

Todas ellas indican que las Tradiciones figuran en el mundo no hispano-hablante como un valor internacional a cuya lectura, sin embargo, mayormente solo se puede acceder a través de la lengua original, lo que sin duda limita la recepción del autor.

3) Una tercera afirmación hace referencia a la multiforme circulación, es decir, la diversidad de formato, soporte y volumen de las Tradiciones: 


\section{Tipología por volumen de edición}

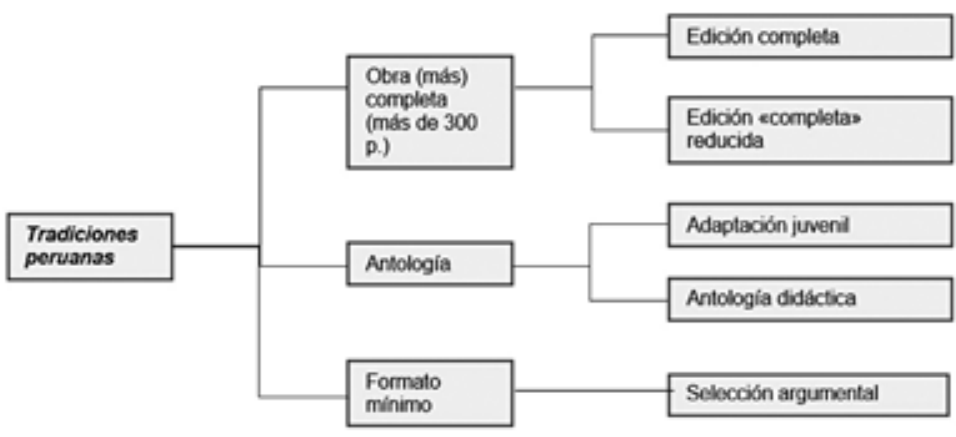

\section{Tipología de formato}

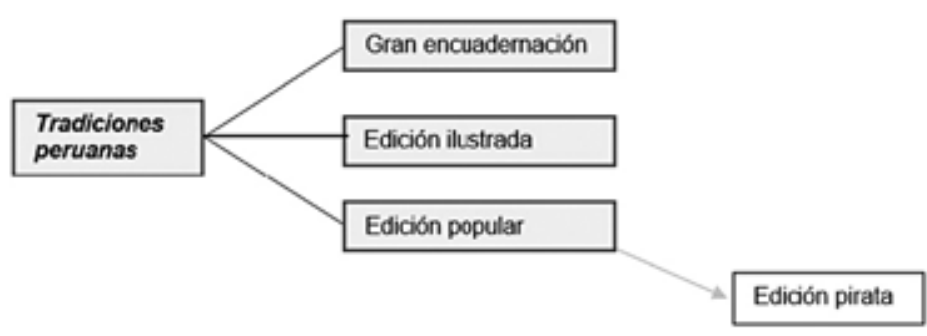

Tipología de soporte

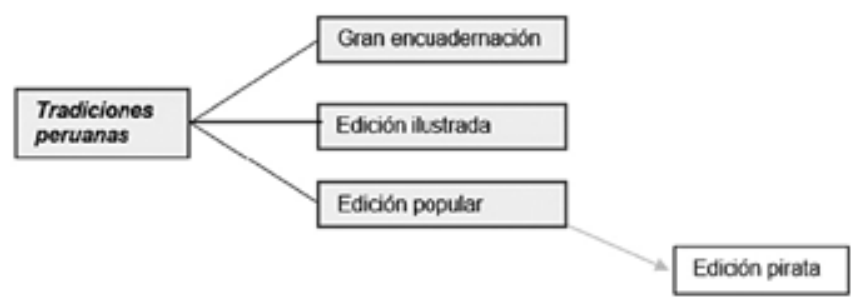


4) En cuarto lugar, destaca el papel que inicialmente desempeñó en la difusión de la obra el editorialismo no peruano, sobre todo el español y argentino: EspasaCalpe, Maucci, Kapelusz, Eudeba, Montaner y Simón, Cátedra, Editorial Vasco- americana, Mesta y, sobre todo, Aguilar, con su edición completa en un solo volumen que, como se sabe, prologó Edith Palma. Las diferentes impresiones españolas (en Madrid, Barcelona, Bilbao, Algete, Cáceres, Santiago) totalizan una treintena de ediciones, mayormente de gran volumen (por encima de las 400 páginas), e igual cantidad, una treintena larga, representan las ediciones argentinas (en Buenos Aires), si bien estas son de menor volumen. Y para calibrar el papel desempeñado por editoriales no peruanas, también es justo señalar que alguna edición española (Madrid, Espasa-Calpe, 1919 y 1930) fue realizada bajo los auspicios del gobierno peruano, lo que debe considerarse como prueba de la consideración de la obra palmista como bien nacional que se debía difundir y propagar. A partir de 2000 predomina la edición peruana -una cincuentena- en gran parte de menores proporciones.

Otros lugares de la edición internacional de las Tradiciones han sido Bogotá (2), Méjico (7), Caracas (3), El Salvador (3), Santiago de Chile (4), La Habana (2), es decir, prácticamente todo el ámbito del espacio hispano-hablante.

5) El hecho de que el estado peruano haya intervenido en algunas ediciones educativas o con fines de difusión literaria (Lima 2008, Ministerio de Educación, 5 l p.) es indicativo de un valor añadido de la escritura de Palma: el de su virtualidad didáctica.

6) Las "ediciones completas" han tenido una edad de oro en los años centrales del siglo XX, destacando las de 
Lima (Castrillón Silva y ed. Cultura Antártica) y la mencionada de Aguilar (1952, Madrid), que editó y prologó la nieta del autor Edith Palma y que alcanzó numerosas reediciones. Desde los años 20 del XX al 2000 han sido una treintena de ediciones completas las que se editaron. A partir de 2000 empieza a predominar la edición antológica.

7) Dato interesante en la historia editorial de las Tradiciones son las ediciones en castellano publicadas en ámbitos no hispanoparlantes, tales como

- la edición alemana de Heidelberg (J. Groos, 1927), con vocabulario y notas;

- las ediciones francesas de París/Brujas (1938), que publica el diplomático peruano García Calderón en Desclée de Brower, y de 1954 en Nathan, de solo 31 p.;

- las ediciones inglesas: de Chicago/New York/ Boston (1936) en Benj. H. Sanborn \& Co.; texto en español con introducción, notas y vocabulario en inglés; la de Londres y New York (1969), en Pergamon Press. El aparato lingüístico que las acompaña hace creer que estas ediciones se han puesto al servicio de la enseñanza del español. ¿O quizás son traducciones sui generis?

8) El hecho de que las Tradiciones hayan entrado en bibliotecas virtuales internacionales, como son la española Biblioteca Virtual Cervantes (http://www. cervantesvirtual.com/portales/ricardo_palma/), el Gutenberg project (http://www.gutenberg.org/ ebooks/2 1282), la Wikisource (https://es.wiki source.org/ wiki/Portada) o la Biblioteca Universal Virtual (https: // www. biblioteca.org.ar/ libros/71164.pdf), sin duda, alude a su calidad de clásico de la literatura universal; 
9) Muchas de las ediciones repiten numerosas reimpresiones o reediciones en un número realmente considerable y hacen de las Tradiciones un caso único en el editorialismo de las letras hispanas. A título de información mencionaré el caso de la edición completa de Aguilar que ya en 1968 iba por la $6^{\text {a }}$ reedición o la de Cátedra que en el espacio de veinticinco años va por la $6^{\mathrm{a}}$ reedición, esto en una época en la que la lectura no es uno de los vicios sociales más destacados.

10) El formato de las ediciones, que va de las 20/30 páginas de las ediciones educativas hasta las 1700 de las ediciones completas pasando por las de formato medio, de 100 a 300, alude al mayor o menor grado de implicación receptora en el lector: un lector inicial, quizás juvenil utiliza una versión reducida, de ingreso, por así decirlo, a la personalidad de Palma; el lector más evolucionado y que ha sacado el gusto por la lectura de las Tradiciones opta por la antología; finalmente, un lector estudioso que es capaz de adquirir la costosa edición completa de Aguilar, Montaner o Calpe.

11) Significativos y de gran transcendencia crítica y de recepción social en el editorialismo de las Tradiciones son tanto el aparato crítico como lo que podríamos llamar el atrezzo editorial. Los epitextos que una veintena larga de grandes plumas y de destacados estudiosos de las Tradiciones han aportado tanto en las ediciones críticas, como en las completas o en las antologías constituyen un interesante corpus ricardopalmista y al tiempo un testimonio de su dimensión nacional: Clemente Palma, Edith Palma, Rubén Darío, Porras Barrenechea, García Calderón, Rodríguez Rea, Dora Bazán, Julio Ortega, González Vigil, Pedro Díaz, Alberto Sánchez, Burneo Barreto, Carlos Garayar, Carlos Villanes, 
Bryce Echenique, etc. Lo mismo puede decirse de ese apartado del paratexto que es la ilustración. Las ilustraciones ante litteram de Pancho Fierro y las ad hoc del cineasta e ilustrador español Fernando Marco son las más características. Por la ilustración de portada, es decir, por la transmutación de la semiosis literaria a la semiosis visual (lo que Jacobson denominó traducción intersemiótica), han pasado todas las interpretaciones, ideológicas o no, de las Tradiciones: desde la deliciosa ilustración historicista del valenciano Fernando Marco a la para-indigenista de la edición vasco-americana pasando por la costumbrista de Fierro, la naif de David Crispín o la verista de Prado- Rayme, las portadas revelan la polisemia del sistema tradicionista de Palma.

\section{La traducción como universalización de la obra}

Todos estos datos son sin duda positivos, pero no dejan de revelar algunos matices negativos, resumibles en un cierto carácter caótico de lo que podríamos llamar el mini-editorialismo. Muchas de estas ediciones podríamos denominarlas "minimalistas", es decir, de escasas, incluso mínimas dimensiones, con un número de páginas inferior a 150, y algunas de escasísimo formato (entre 20, 50 u 80 páginas), lo que, si consideramos el volumen integral de la obra (en torno a las 1.500 págs.), difícilmente pueden dar una visión completa de la escritura del limeño. Sobre todo teniendo en cuenta la diversidad de contenido, de forma y formato. Lo cual debe llevar a cuestionarse los criterios de selección, que quizás no sean siempre eficaces a la hora de proporcionar al lector una idea global del hacer literario de Palma. Eficaz nos parece la edición temática: Tradiciones de crimen y espanto (2015, Santillana, 46 p.) o Tradiciones de Emancipación de González Vigil, que manifiestan un buen criterio de selección. 
En efecto, la difusión de sus obras lo hace uno de sus grandes escritores de las letras hispánicas. Pero, si es indiscutible que las Tradiciones son un bien hispánico, no es menos cierto que están todavía muy distantes de ser una obra universal... por el simple hecho de que al día de hoy solo figuran traducidas en media docena de lenguas. Si lo comparamos con las lenguas en las que están presentes las obras de Vargas Llosa (70 lenguas), las versiones de la obra de RP resultan casi ridículas, sobre todo si se tiene en cuenta el significado nacional y transnacional del miraflorino. La traducción, es decir, el llevar a las otras orillas lingüísticas la obra de Palma, hoy en día ya no puede ser tarea del autor, que quizás solo pensó como lector implícito el peruano o el hispano- hablante. Y es escandaloso que solo figure, muy parcialmente, traducido en francés (x2), bengalí, inglés, italiano, rumano, chino, árabe, portugués y, de una forma muy peculiar, en alemán. Tras laboriosos sondeos en los catálogos internacionales, he podido identificar el número de traducciones, que indican el estado, escaso, de universalización de la obra de Palma. Los tres primeros documentos que aducimos pueden considerarse pseudo-traducciones, pues son ediciones en español con notas y vocabulario en las respectivas lenguas:

\section{Pseudotraducciones:}

+-(1928) Tradiciones peruanas. Heidelberg, Groos. Texto español, notas y vocabulario español-alemán, 1928, 60 págs.

+-(1936) Tradiciones peruanas. Chicago, New York; Boston : Benj. H. Sanborn \& Co. Texto en español; introducción, notas y vocabulario en inglés.

+-(1987) Tradiciones peruanas. Authorized edition, with introduction, notes and vocabulary G. W. Umphrey Ann Arbor, Michigan, University Microfilms International, 242 p. reed. de la anterior. 


\section{CASI SIGLO Y MEDIO DE RECEPCIÓN TRADICIONISTA: UNIVERSALIDAD O internaCionalidad de Ricardo Palma}

Traducciones propiamente dichas

-(1938) Traditions peruviennes. París, Institut International de Coopération Intellectuelle. Trad. Mathilde Pomès. 260 págs.

-1945 The Knights Of the Cape and Thirty-Seven Other Selections From the Tradiciones Peruanas. Knopf, N. York, 246 págs.

-(1958) Traducción china ((¿秘魯翻譯 Bìlǔ fānyì?. Peking, 170 págs. Otra eventual edición más reciente en chino no la hemos podido identificar, pero nos consta su existencia.

-(1979) Traditii peruane. Trad. de Casandra Maria Greceanu. Bucarest, Minerva, BPT serie noua. 343 pags.

-(1992), Annais da Inquisiçao de Lima. São Paulo: Edusp. 142 págs.

-(2001) Tradizioni Peruviane. Raconti della terra degli incas. Napoli: Liguori. 169 págs.

-(2004) Peruvian Traditions. USA: Oxford U. Press. 263 págs.

-(2002) Traditions peruviennes. Bordeaux: Presses Universitaires de Bordeaux. 256 págs.

-(2012) Paramparāìa Perura kāhinī (bengalí). Trad. Rāẏ, Aśesh. Cyātārīī, Atasī. Kalakātā (Calcuta), edición bilingüe.

-(2019) Tradiciones peruanas. Antología bilingüe. Trad. al árabe de Taha Ziada. Lima, URP.

En total se registran dos versiones francesas, dos inglesas, una rumana, una en bengali, dos en chino, una en árabe, una italiana y una portuguesa. Como se aprecia, el décalage entre la presencia de las Tradiciones en el ámbito hispano y la presencia que tienen en el ámbito hispano-hablante es evidente. Todavía, 
como advertía hace dos años en este mismo foro, son muchos los ámbitos lingüísticos en los que está ausente la obra de Palma: el sueco, el griego, el holandés. ¿Acaso no representa Palma para el Perú lo que, por ejemplo, Selma Lagerlof fue para Suecia? ¿No merecería estar vertido dignamente al alemán? ¿No sería de desear que RP se convirtiera en patrimonio literario universal a través de una serie de versiones en otras lenguas con gran número de hablantes... y de lectores: suahili, turco, búlgaro, checo u holandés? Alguien, algunos han dicho y han dicho bien, que la traducción, es decir, la versión en lengua extranjera de las obras literarias construye la literatura universal. Y para que una obra se vierta a una lengua extranjera deben conjurarse una serie de factores extrínsecos que, sobre la base de una calidad intrínseca, la hagan pasar al mercado literario global: 1) el editor, 2) el crítico y, 3) el traductor.

Dado que la crítica a Palma le ha sido suficientemente favorable; dado que traductores habría a cientos que podrían encargarse de la versión a cada una de las lenguas, aunque la tarea no fuera fácil; dado que existen potenciales editores y dado que Palma, obviamente, no puede fomentar su propia obra, ipor qué las instancias pertinentes, peruanas o no, no intentan promocionar la difusión internacional de las Tradiciones? En el momento actual, a las Tradiciones, cuando ya existe un número significativo de ediciones completas, críticas y populares, les ha llegado la hora de la universalidad, de la versión a lenguas y ámbitos culturales en los que todavía no están presente. ¿̇No sería el modelo de ayudas a la traducción existentes en países como Francia, España, Alemania, un modelo a seguir aquí en el Perú? Quizás el año centenario de RP habría sido una buena ocasión para fomentar la versión de sus Tradiciones a muchas otras lenguas en las que literariamente RP todavía no existe. Nuestra universidad, la URP, ha hecho lo suyo al fomentar la traducción al árabe. Otras instituciones podían seguir el ejemplo. 


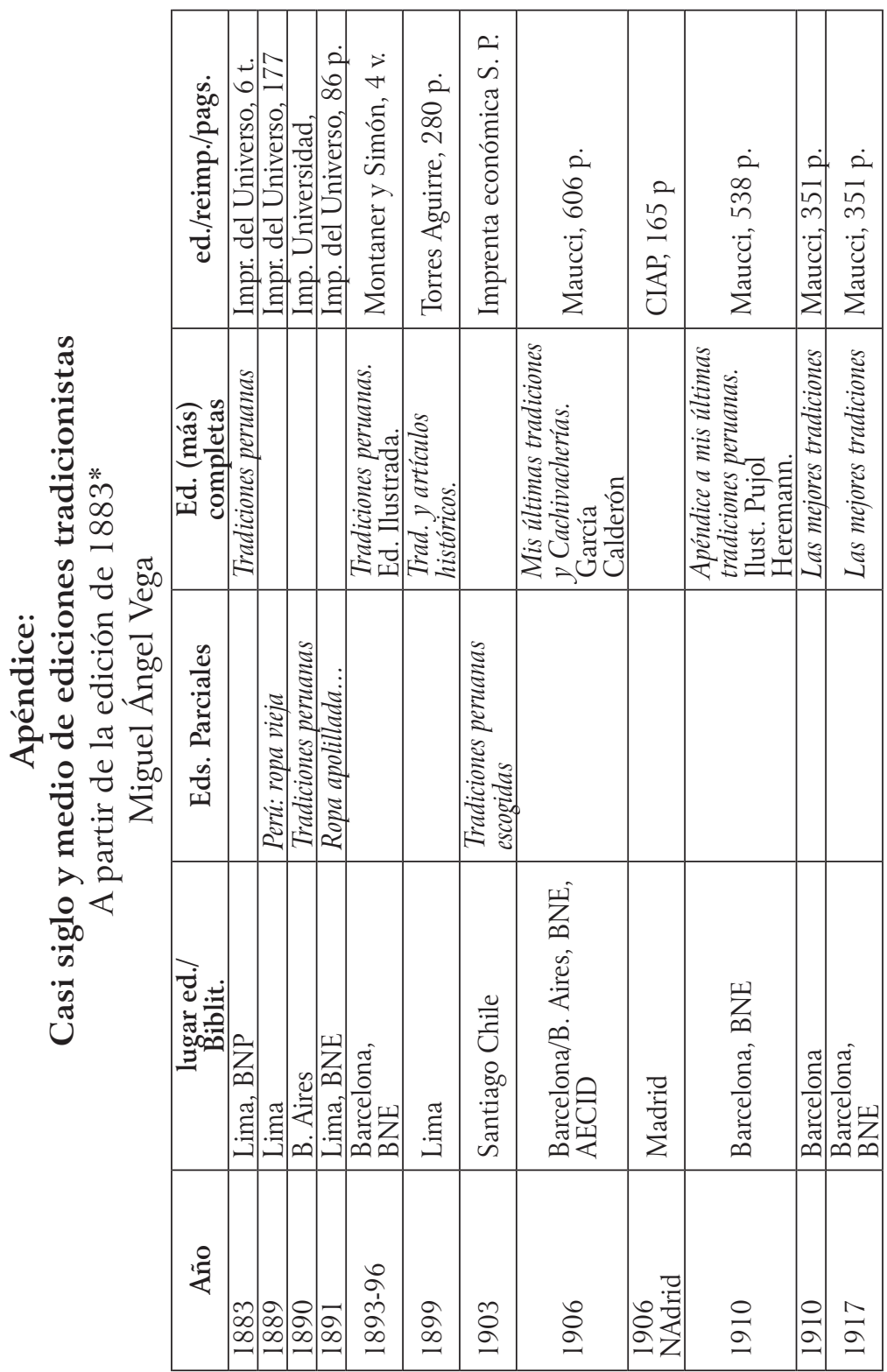




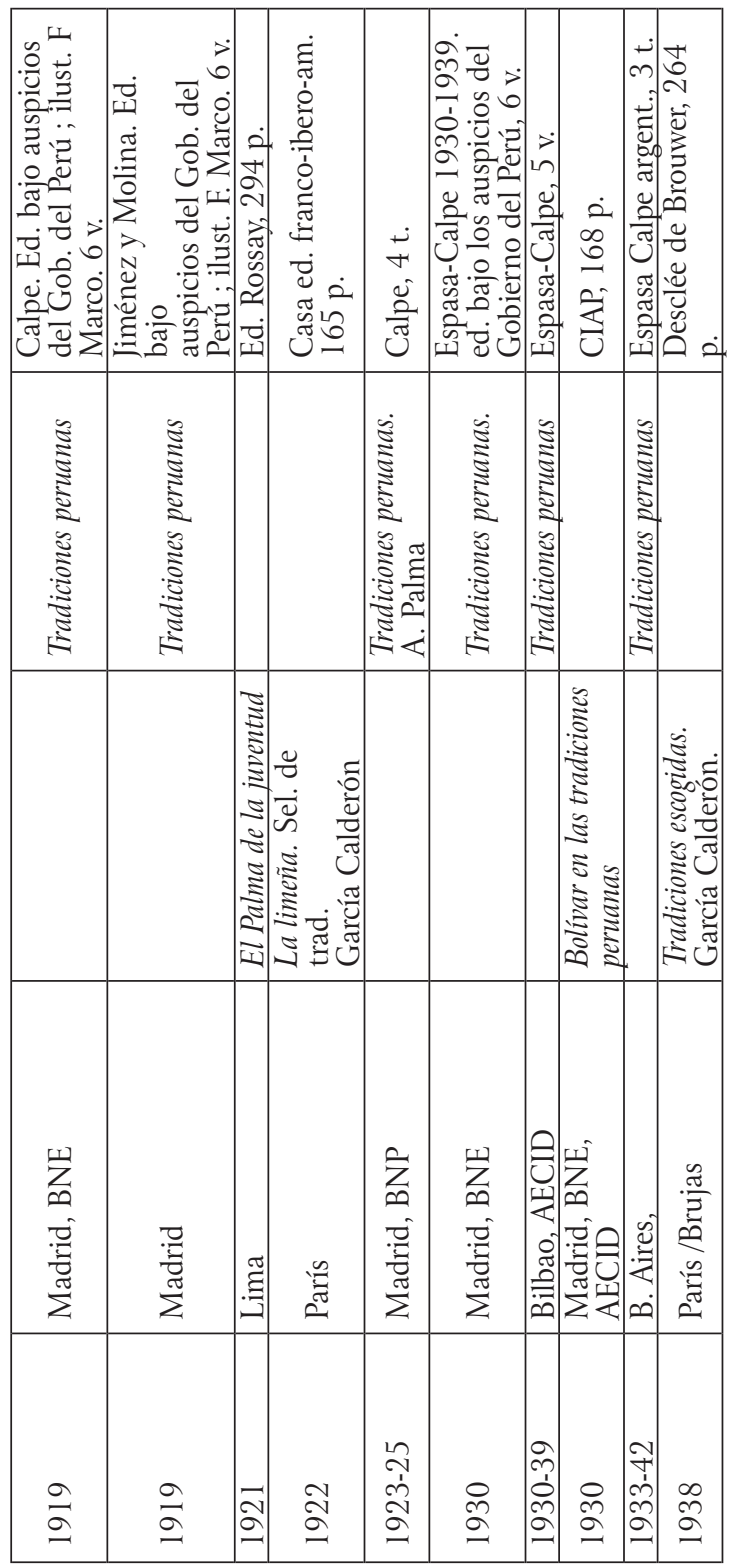

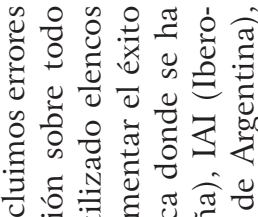

ช.

乙

$\dot{\mathcal{D}} \Xi$ ปี

胥

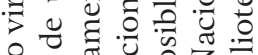

ㅇ. 늘

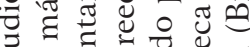

s 워

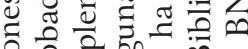

을

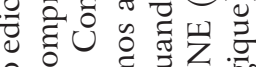

- 0 म ह

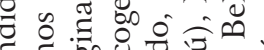

ఫ

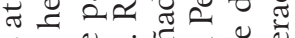

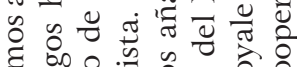

పิ

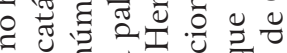

శే

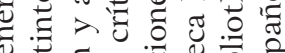

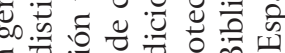

ปี

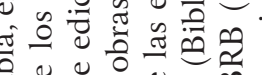

जै च \&

ฐี

ช

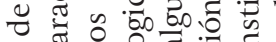

־

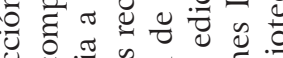

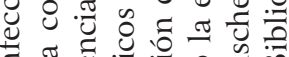

๘ี

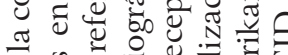

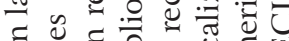

至 


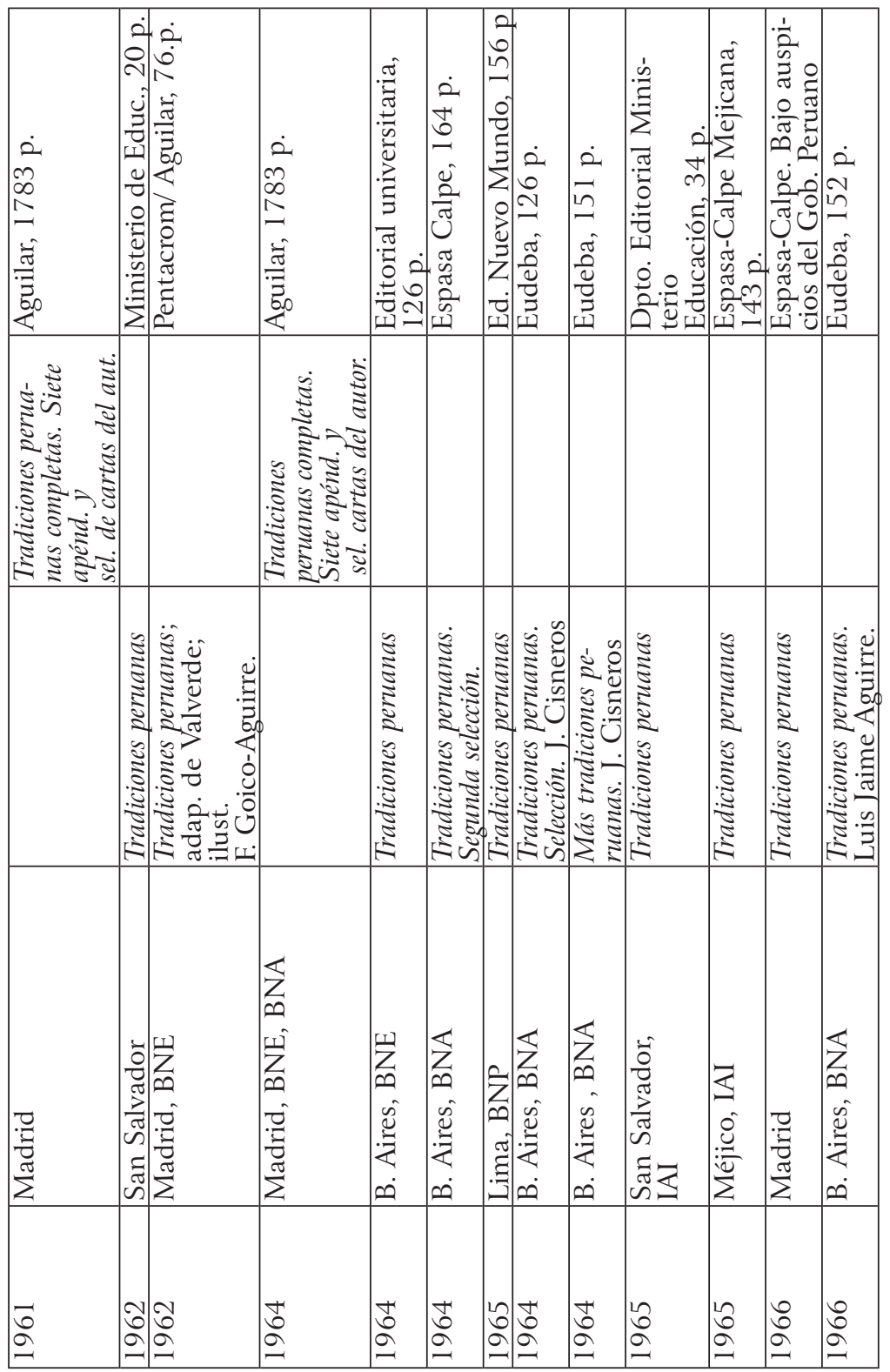




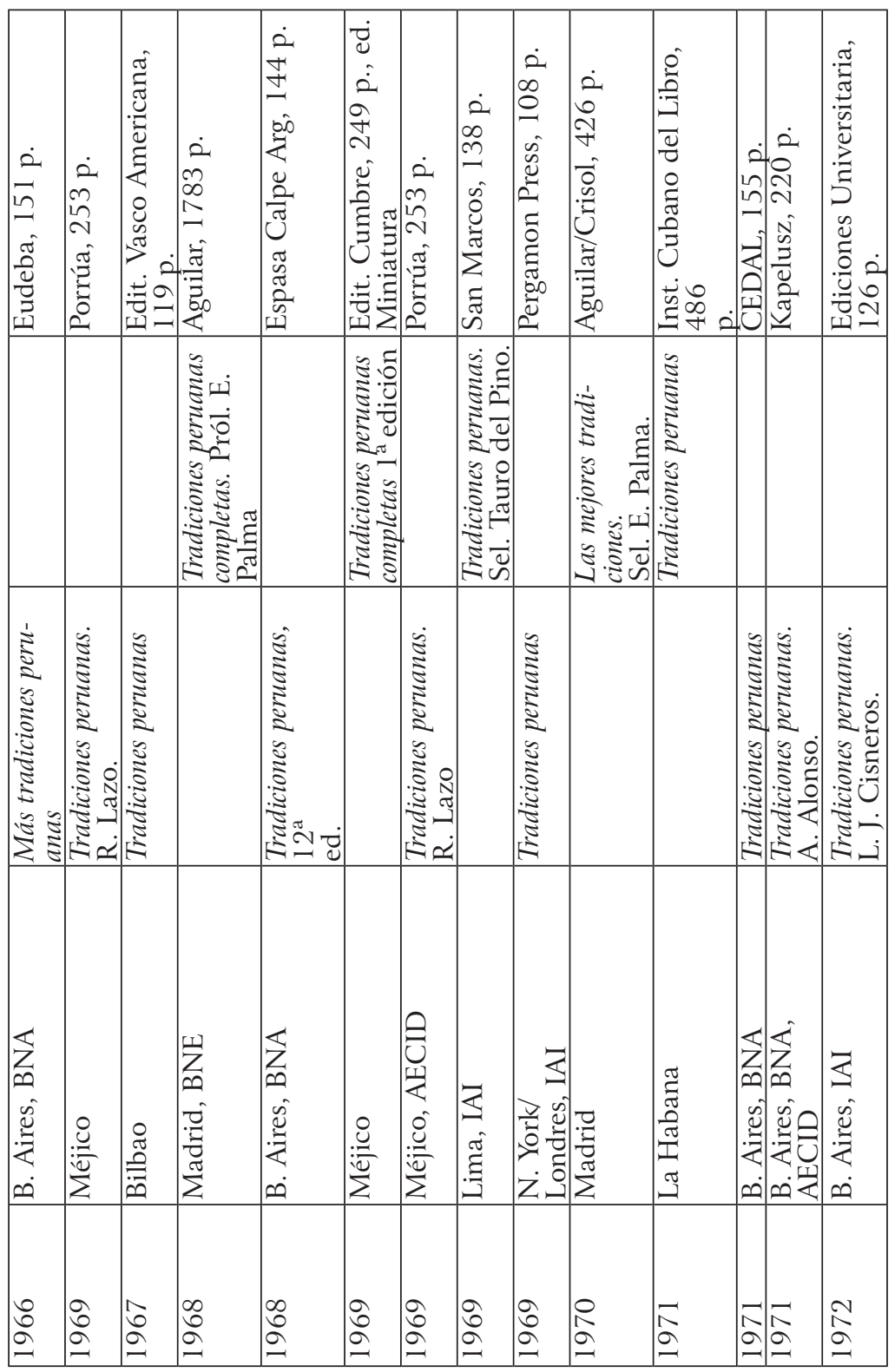




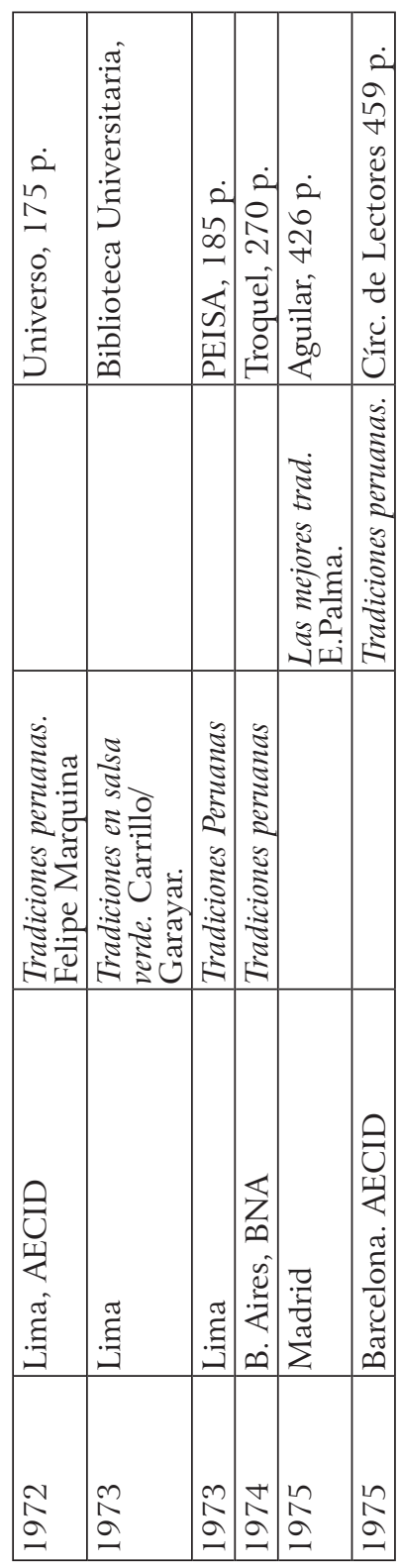




\begin{tabular}{|c|c|c|c|c|c|c|c|c|c|c|c|c|}
\hline & 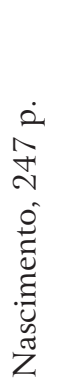 & $\begin{array}{l}\dot{e} \\
\text { N } \\
\text { m } \\
\tilde{\tilde{s}} \\
\dot{\omega} 0\end{array}$ & 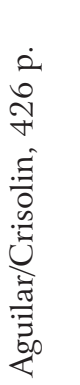 & 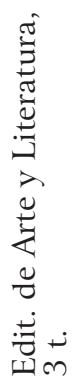 & 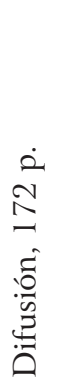 & 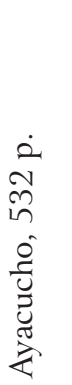 & 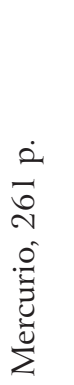 & 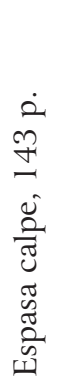 & $\begin{array}{l}\dot{e} \\
\stackrel{v}{ }\end{array}$ & 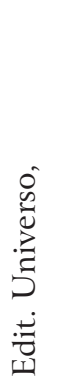 & 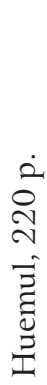 & 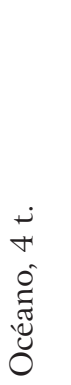 \\
\hline 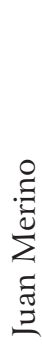 & & & 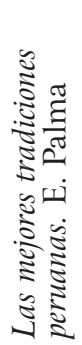 & 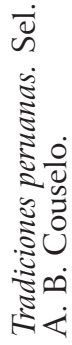 & & 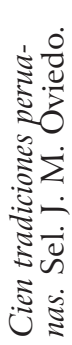 & & & & & & 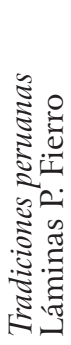 \\
\hline & 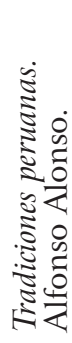 & 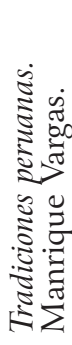 & & & 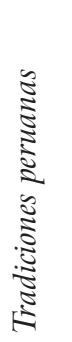 & & 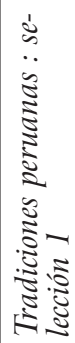 & 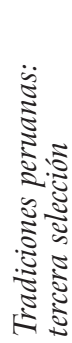 & 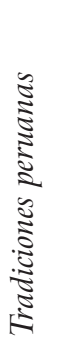 & 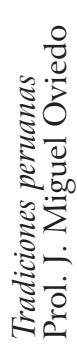 & 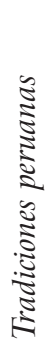 & \\
\hline & 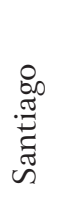 & 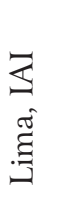 & 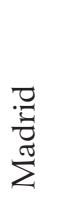 & 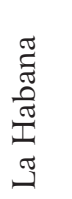 & 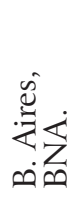 & 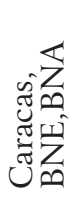 & 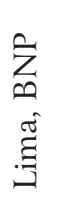 & 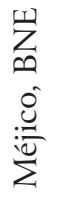 & 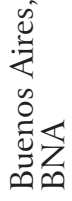 & 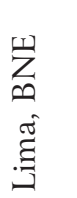 & $\begin{array}{l}\mathscr{U} \\
\stackrel{Z}{Z} \\
\dot{0}\end{array}$ & 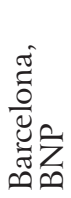 \\
\hline & $\stackrel{10}{\Omega}$ & 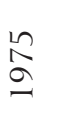 & $\begin{array}{l}\text { @ } \\
\hat{\Omega}\end{array}$ & 合 & $\hat{\Omega}$ & $\stackrel{\curvearrowright}{\Omega}$ & $\begin{array}{l}\infty \\
\hat{\Omega} \\
-\end{array}$ & $\begin{array}{l}\infty \\
\stackrel{N}{2}\end{array}$ & $\begin{array}{l}\Omega \\
\hat{\Omega}\end{array}$ & 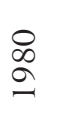 & $\begin{array}{l}\vec{\infty} \\
\curvearrowright\end{array}$ & $\begin{array}{l}\text { } \\
\curvearrowright \\
\approx\end{array}$ \\
\hline
\end{tabular}




\begin{tabular}{|c|c|c|c|c|c|c|c|c|c|c|c|c|}
\hline 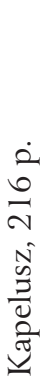 & 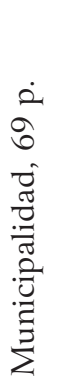 & 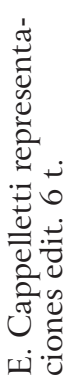 & 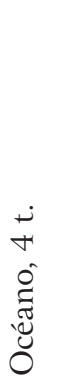 & 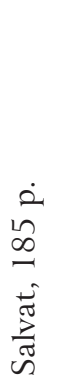 & 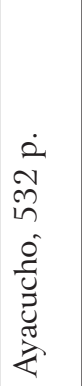 & 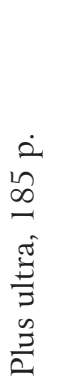 & 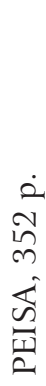 & 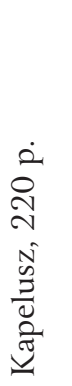 & 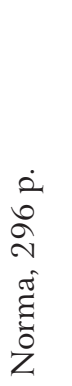 & 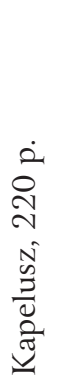 & $\begin{array}{c}\dot{0} \\
\infty \\
10 \\
\dot{0} \\
\dot{0}\end{array}$ & $\begin{array}{l}\dot{2} \\
\infty \\
10 \\
\dot{v} \\
\dot{u}\end{array}$ \\
\hline & & 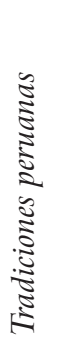 & 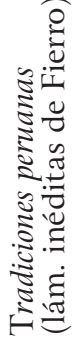 & & 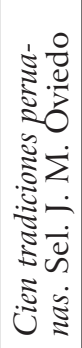 & & 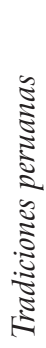 & & & & 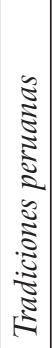 & 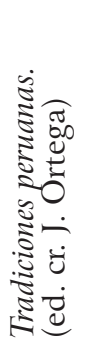 \\
\hline 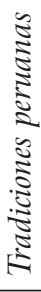 & 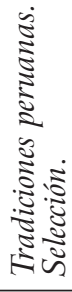 & & & 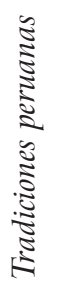 & & 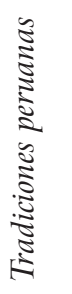 & & & 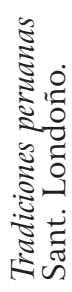 & 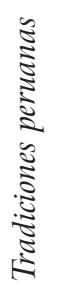 & & \\
\hline $\begin{array}{l}\stackrel{2}{Z} \\
\dot{Z} \\
\dot{2}\end{array}$ & $\stackrel{\widetilde{\Xi}}{\Xi}$ & $\stackrel{\widetilde{\Xi}}{\Xi}$ & 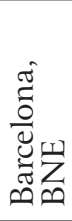 & 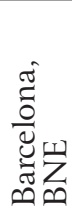 & 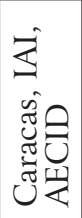 & 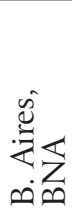 & $\stackrel{\widetilde{Z}}{\Xi}$ & 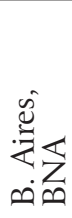 & 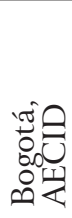 & 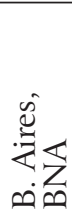 & 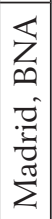 & 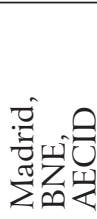 \\
\hline $\begin{array}{l}\text { N } \\
\curvearrowright \\
\approx\end{array}$ & $\begin{array}{l}m \\
\infty \\
a\end{array}$ & $\begin{array}{l}\infty \\
\infty \\
\approx\end{array}$ & $\begin{array}{l}\stackrel{+}{\infty} \\
\curvearrowright\end{array}$ & $\begin{array}{l}\stackrel{+}{\infty} \\
\curvearrowright\end{array}$ & \begin{tabular}{l}
$\Omega$ \\
$\infty$ \\
\hdashline
\end{tabular} & $\begin{array}{l}n \\
\infty \\
\approx\end{array}$ & $\begin{array}{l}\curvearrowright \\
\curvearrowright\end{array}$ & $\widehat{\Omega}$ & $\vec{\sigma}$ & $\stackrel{m}{\sigma}$ & $\begin{array}{l}m \\
\hat{\sigma}\end{array}$ & $\stackrel{n}{\Omega}$ \\
\hline
\end{tabular}




\begin{tabular}{|c|c|c|c|c|c|c|c|c|}
\hline 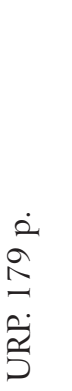 & 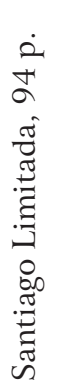 & 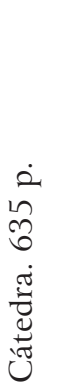 & 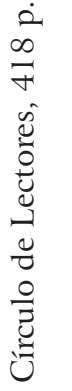 & 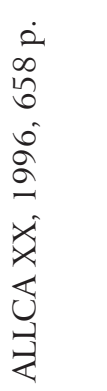 & 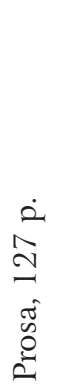 & $\begin{array}{l}\stackrel{2}{o} \\
\stackrel{N}{N} \\
\stackrel{Z}{Z} \\
\infty\end{array}$ & 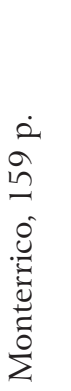 & $\begin{array}{l}\dot{e} \\
\hat{N} \\
m \\
\frac{0}{0} \\
\overrightarrow{0} \\
0 \\
0 \\
0\end{array}$ \\
\hline & & 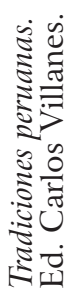 & & 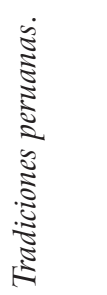 & & & & 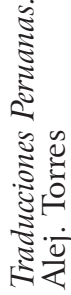 \\
\hline 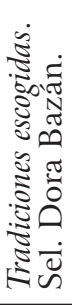 & 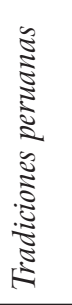 & & 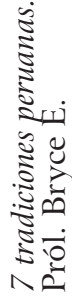 & & 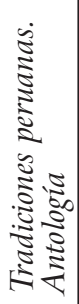 & 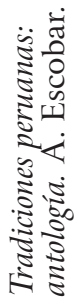 & 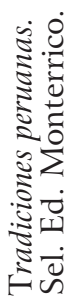 & \\
\hline 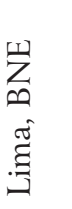 & 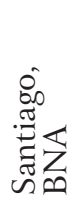 & 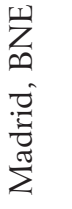 & 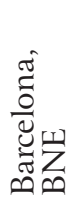 & 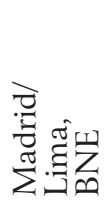 & 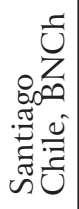 & 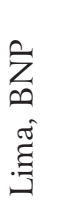 & 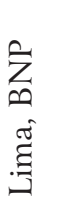 & 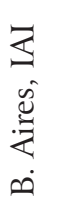 \\
\hline$\stackrel{\vec{\sigma}}{2}$ & $\stackrel{+}{2}$ & $\stackrel{\text { aे }}{2}$ & $\stackrel{1}{\Omega}$ & $\stackrel{\circ}{\curvearrowright}$ & $\stackrel{2}{2}$ & $\hat{\sigma}$ & مૂ & ڤ̊ \\
\hline
\end{tabular}




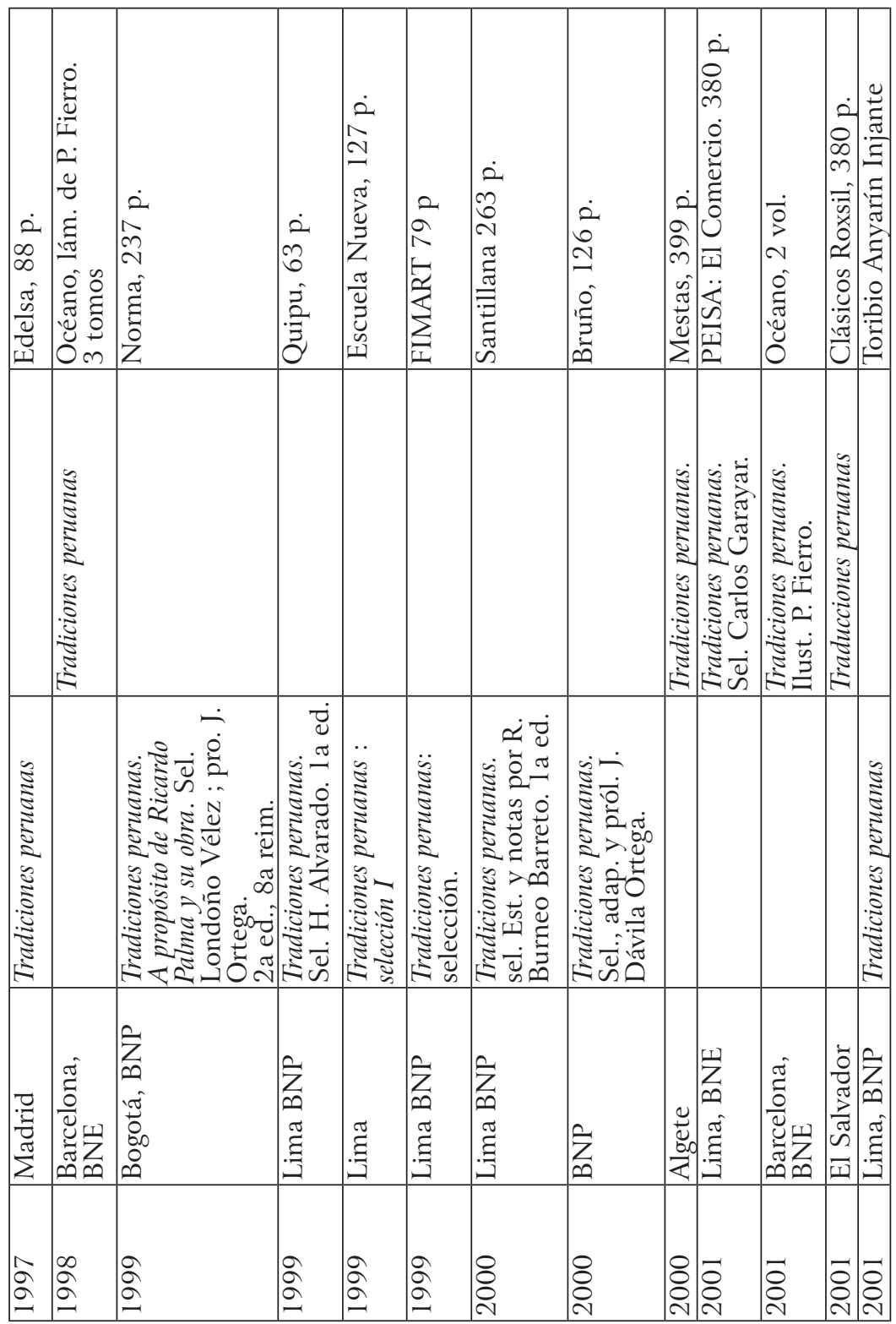




\begin{tabular}{|c|c|c|c|c|c|c|c|c|c|c|c|c|}
\hline 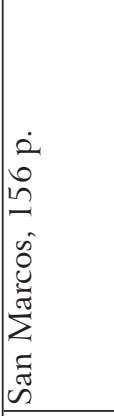 & 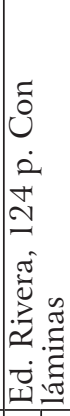 & 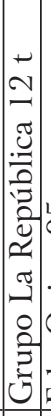 & 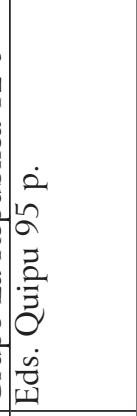 & 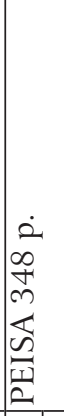 & 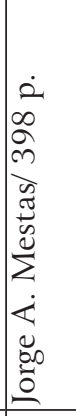 & 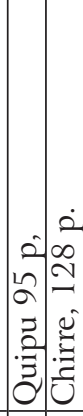 & 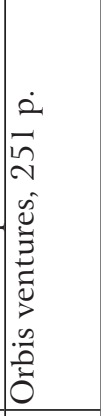 & 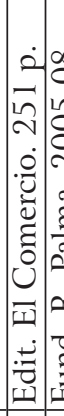 & 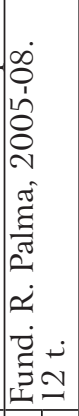 & 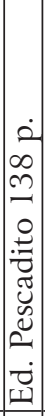 & 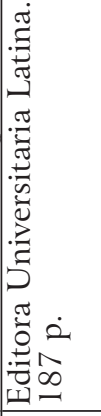 & 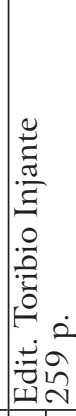 \\
\hline & & 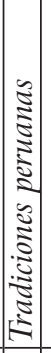 & & 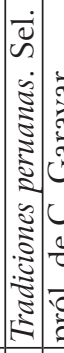 & & & & & 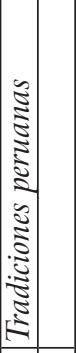 & & & \\
\hline 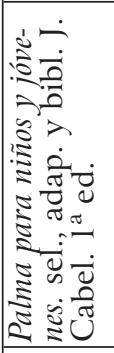 & 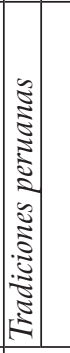 & & 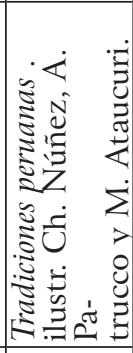 & & 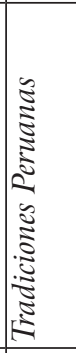 & 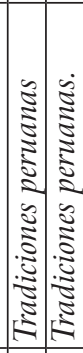 & 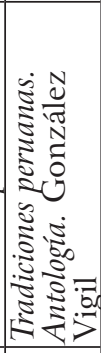 & 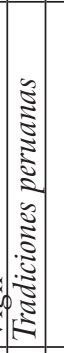 & & 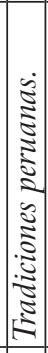 & 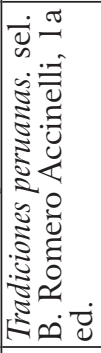 & 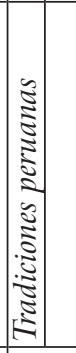 \\
\hline$\stackrel{\widetilde{\Xi}}{\Xi}$ & 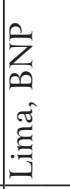 & 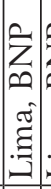 & 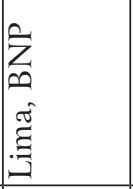 & $\stackrel{\widetilde{\pi}}{\Xi}$ & 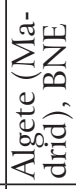 & 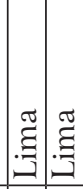 & $\stackrel{\widetilde{\pi}}{\Xi}$ & & $\stackrel{\widetilde{a}}{\Xi}$ & 节 & $\stackrel{\tilde{\sigma}}{\Xi}$ & $\stackrel{\widetilde{Z}}{\Xi}$ \\
\hline$\underset{\sim}{\stackrel{8}{2}}$ & ָ̃ & $\mid$ & ঠ & $\underset{\sim}{8}$ & $\underset{\sim}{8}$ & 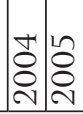 & 旅 & 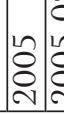 & 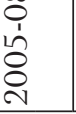 & \begin{tabular}{l}
8 \\
\multirow{2}{*}{} \\
\end{tabular} & $\begin{array}{l}0 \\
0 \\
0 \\
\text { d } \\
\end{array}$ & ֻ \\
\hline
\end{tabular}




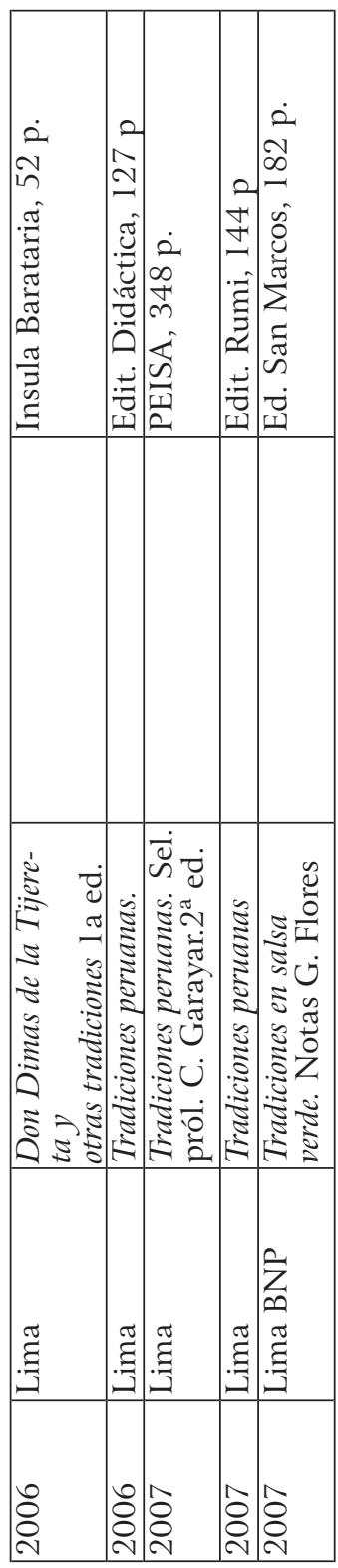




\begin{tabular}{|c|c|c|c|c|c|c|c|c|c|c|c|}
\hline 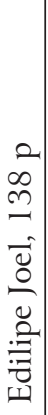 & 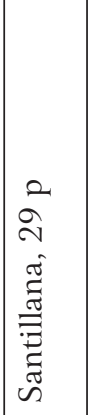 & 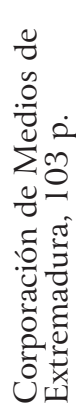 & 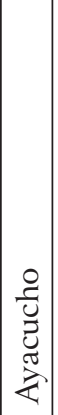 & $\stackrel{\dot{2}}{\stackrel{0}{n}}$ & 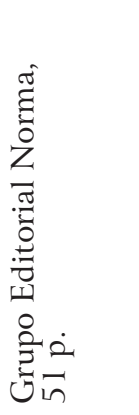 & 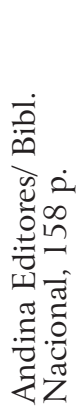 & 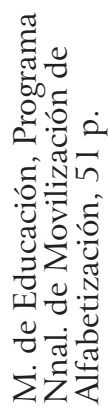 & 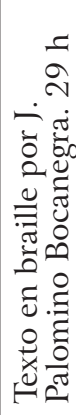 & 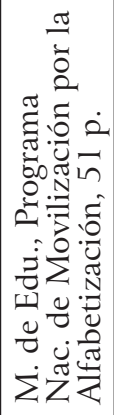 & 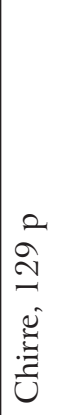 & 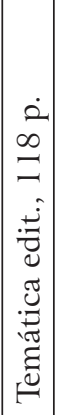 \\
\hline & & & & 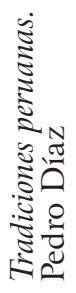 & & & & & & & \\
\hline 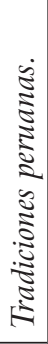 & 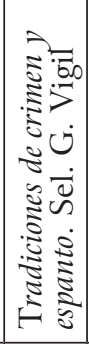 & 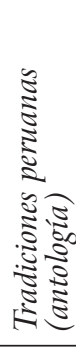 & 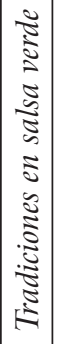 & & 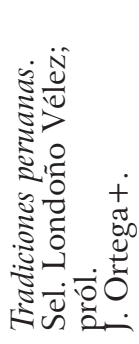 & 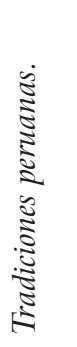 & 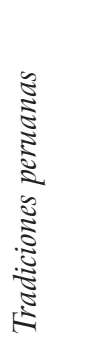 & 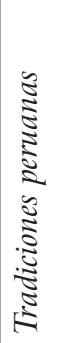 & 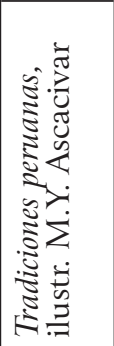 & 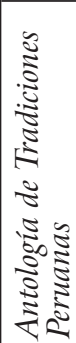 & 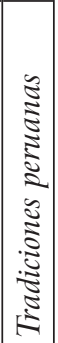 \\
\hline $\begin{array}{l}\tilde{Z}_{\infty} \\
\tilde{\Xi} \\
\Xi \\
\Xi\end{array}$ & 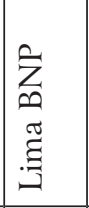 & 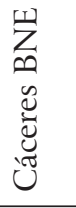 & 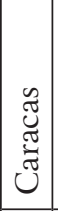 & $\underset{\Xi}{\Xi}$ & 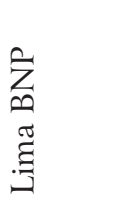 & 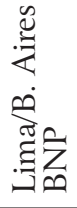 & 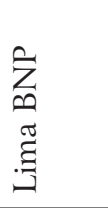 & 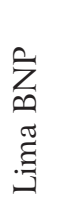 & 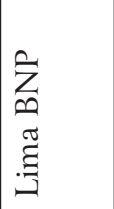 & $\stackrel{\widetilde{Z}}{\Xi}$ & 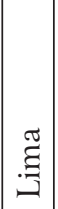 \\
\hline$\stackrel{8}{8}$ & 袊 & ᄋ & 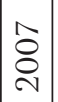 & $\stackrel{\substack{\infty \\
\overbrace{}}}{\circ}$ & $\stackrel{\infty}{\stackrel{\infty}{8}}$ & $\stackrel{\infty}{\stackrel{\infty}{8}}$ & $\stackrel{\infty}{\stackrel{\infty}{8}}$ & $\stackrel{\infty}{\infty}$ & ஓి & ô & 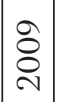 \\
\hline
\end{tabular}




\begin{tabular}{|c|c|c|c|c|c|c|c|c|}
\hline 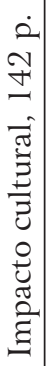 & 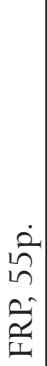 & 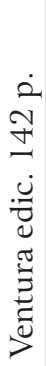 & 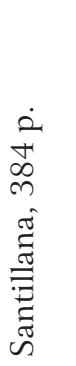 & 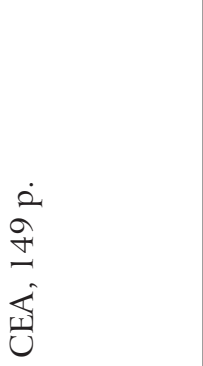 & 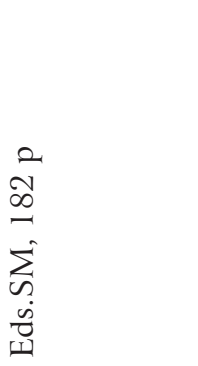 & $\begin{array}{l}+ \\
\infty \\
\hat{\sigma} \\
\tilde{\sigma}\end{array}$ & $\stackrel{\varrho}{\varrho}$ & 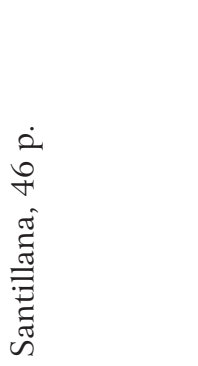 \\
\hline & & & 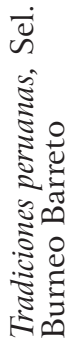 & & & 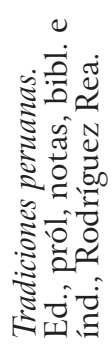 & & \\
\hline 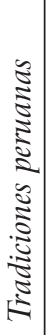 & 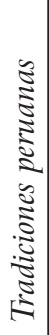 & 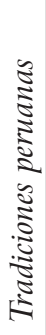 & & 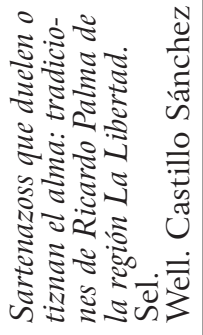 & 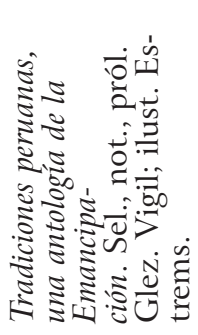 & & 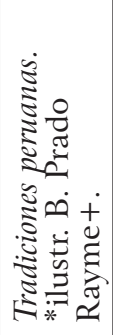 & 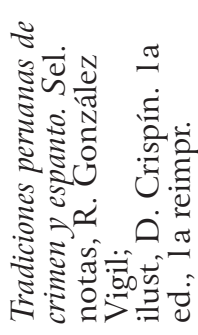 \\
\hline$\underset{\Xi}{\Xi}$ & $\stackrel{\widetilde{\Xi}}{\Xi}$ & 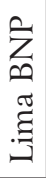 & $\stackrel{\widetilde{J}}{\Xi}$ & $\stackrel{0}{\stackrel{0}{\vdots}}$ & 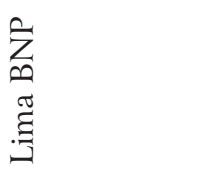 & 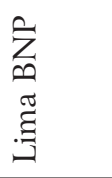 & 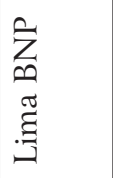 & \\
\hline 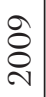 & 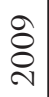 & $\underset{\varpi}{\sigma}$ & $\underset{\sigma}{\sigma}$ & $\underset{\sim}{\stackrel{v}{\sigma}}$ & $\stackrel{m}{\underset{\sim}{\sigma}}$ & $\underset{\sim}{\stackrel{\Xi}{ঠ}}$ & $\stackrel{n}{0}$ & $\stackrel{n}{\underset{0}{0}}$ \\
\hline
\end{tabular}




\begin{tabular}{|c|c|c|c|c|}
\hline 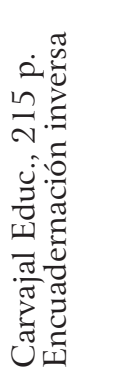 & 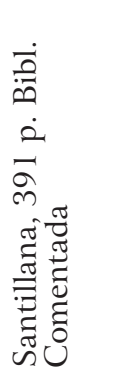 & 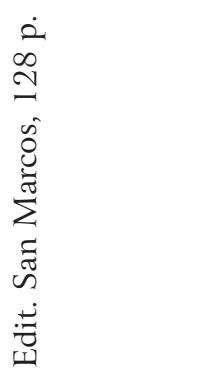 & 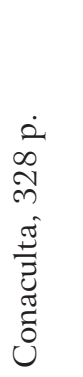 & 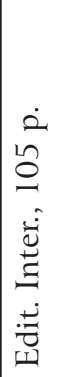 \\
\hline & & & 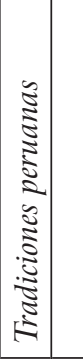 & \\
\hline 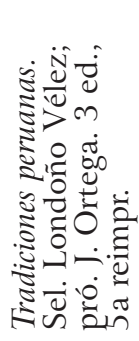 & 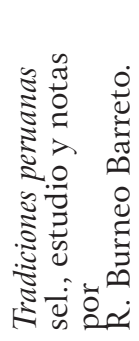 & 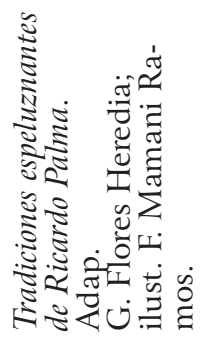 & & 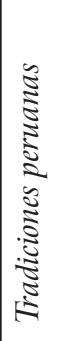 \\
\hline 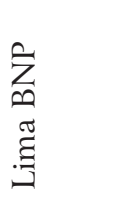 & 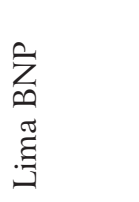 & $\stackrel{\widetilde{\Xi}}{\Xi}$ & 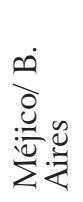 & 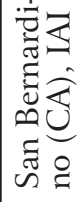 \\
\hline$\stackrel{10}{\stackrel{0}{0}}$ & $\stackrel{\ln }{\stackrel{2}{\sigma}}$ & $\stackrel{n}{\stackrel{n}{0}}$ & $\stackrel{n}{\circ}$ & $\stackrel{10}{\circ}$ \\
\hline
\end{tabular}




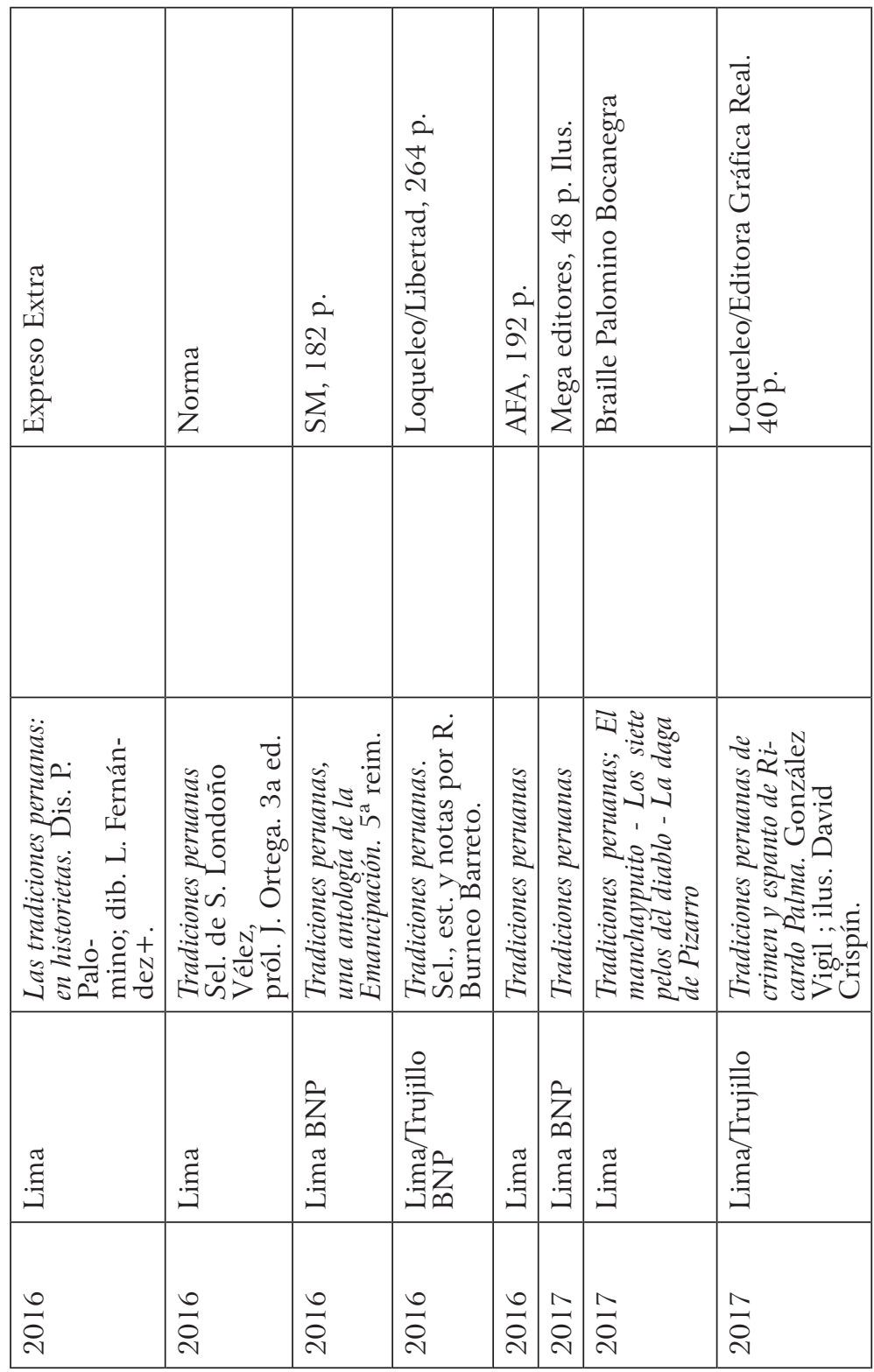




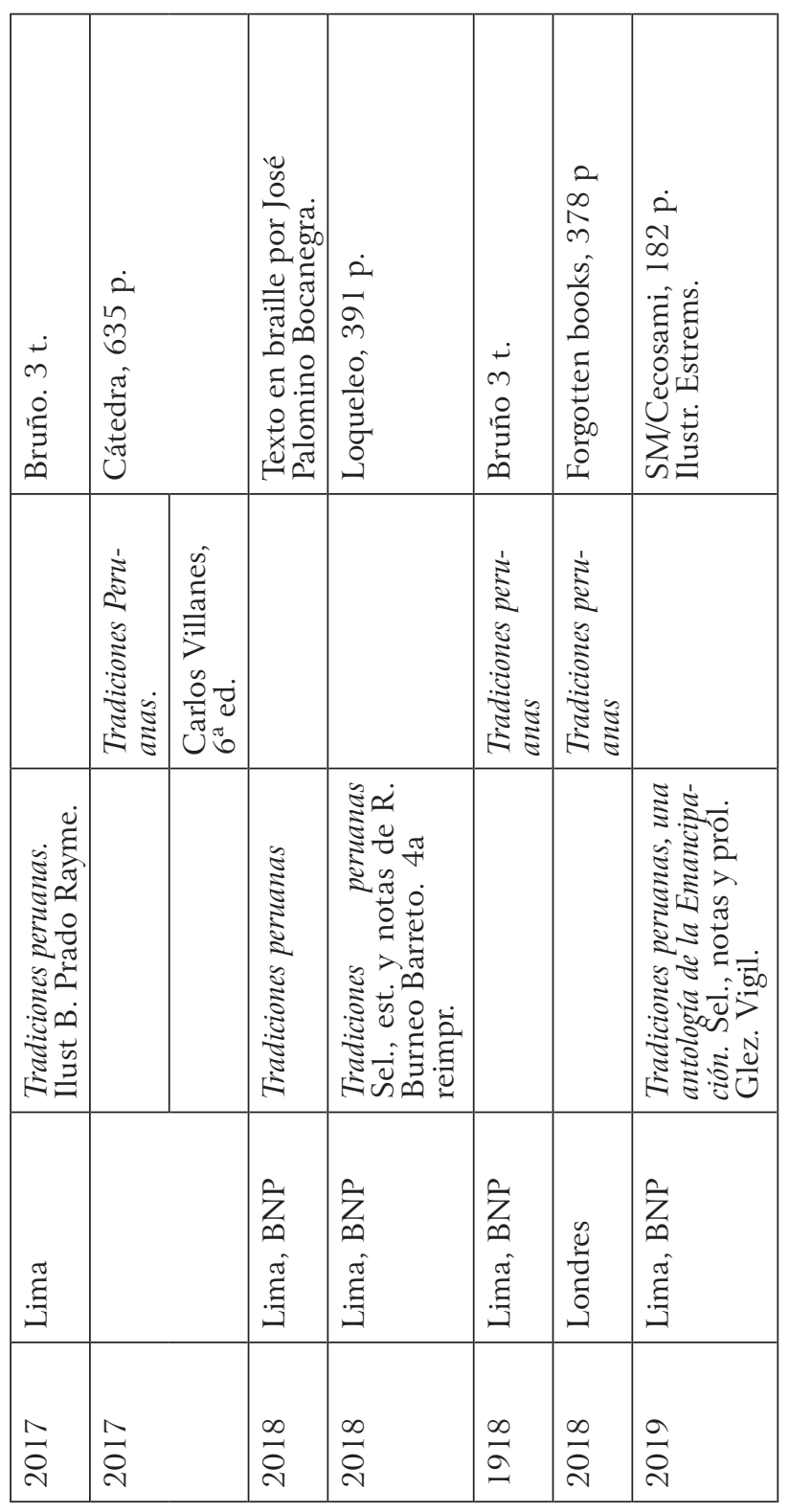

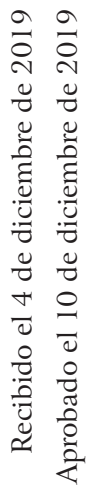

